\title{
El Plan Nacional de Educación y Patrimonio crea la Red Internacional de Educación Patrimonial
}

Fruto del II Congreso Internacional de Educación Patrimonial, que tuvo lugar en octubre de 2014 en Madrid, es la creación de la Red Internacional de Educación Patrimonial / International Network on Heritage Education (RIEP/INHE). Esta red internacional será gestionada desde el Plan Nacional de Educación y Patrimonio y servirá para establecer mecanismos de coordinación, difusión y colaboración en educación patrimonial entre profesionales de diferentes países, instituciones y ámbitos educativos. Contará inicialmente con representantes de 15 países de Europa, América, África y Asia.

Olaia Fontal | Universidad de Valladolid

Alex Ibáñez | Universidad del País Vasco

José María Cuenca | Universidad de Huelva

Lorenzo Martín | Instituto del Patrimonio Cultural de España

URL de la contribución <www.iaph.es/revistaph/index.php/revistaph/article/view/3580>

Fruto del II Congreso Internacional de Educación Patrimonial, que tuvo lugar en octubre de 2014 en Madrid, es la creación de la Red Internacional de Educación Patrimonial / International Network on Heritage Education (RIEP/INHE). Esta red internacional será gestionada desde el Plan Nacional de Educación y Patrimonio y servirá para establecer mecanismos de coordinación, difusión y colaboración en educación patrimonial entre profesionales de diferentes países, instituciones y ámbitos educativos. Contará inicialmente con representantes de 15 países de Europa, América, África y Asia.

La Red Internacional de Educación Patrimonial es una organización de personas, agrupaciones e instituciones que comparten su interés o dedicación a la educación patrimonial desde distintos ámbitos y países. Nace como conclusión al II Congreso Internacional de Educación Patrimonial (Madrid, 28-31 de octubre de 2014) y toma como punto de partida las reflexiones que se generaron en este evento, recogidas en el documento de conclusiones y en el storify del mismo, bajo el hastag \#CIEP2.

La red forma parte de las actuaciones que se están generando desde el Instituto del Patrimonio Cultural de España (IPCE), en el marco del Plan Nacional de Educación y Patrimonio (PNEyP), coordinado desde esta subdirección general, perteneciente al Ministerio de Educación, Cultura y Deporte. Se alojará en la web www.oepe.es así como en la propia web del PNEyP, tras su validación por la comisión de seguimiento del citado Plan que se reunirá en 2015.

La red deriva de los objetivos y fundamentación del Plan Nacional de Educación y Patrimonio, acometiendo aspectos fundamentales de los tres programas en los que éste se articula. Así, pretende incentivar "la presencia de nuestro país en redes actualmente activas que se ocupen de la difusión y comunicación del Patrimonio", objetivo prioritario del PNEyP.

> Dentro del Programa de investigación en educación patrimonial e innovación en didáctica del Patrimonio, concretamente en lo referido al ámbito informal se entiende la red como potencial generadora del "impacto de los medios de comunicación, redes sociales y otros medios virtuales en la formación patrimonial de la sociedad, profundizando en las posibilidades de localización, intercambio, debate y difusión que permiten las tecnologías de la información y comunicación".

> Dentro del Programa de formación de educadores, gestores y otros agentes culturales e investigadores 
en educación patrimonial, responde a la necesidad de "potenciar la creación de redes de colaboración transversal entre grupos de docentes y gestores culturales dedicados a la educación patrimonial, para facilitar el intercambio de experiencias".

> Por último, dentro del programa transversal: difusión, pretende fomentar "la presencia en las principales redes sociales y la adecuada integración de cuantas herramientas y recursos pone a su disposición Internet, creándose foros de debate, grupos de trabajo y propuestas de reflexión".

Por todo ello, la Red Internacional de Educación Patrimonial parte del PNEyP para acometer los programas y líneas de actuación básicos del mismo.

\section{Web de interés}

> Plan Nacional de Educación: <http://ipce.mcu.es/ conservacion/planesnacionales/educacion.html>

$>$ Observatorio de la Educación Patrimonial en España: $<$ http://www.oepe.es/>

> II Congreso internacional de educación patrimonial <http:// www.oepe.es/congreso>

\section{Patrocinadores}

> Proyecto de I+D+i EDU2012-37212, Ministerio de Economía y Competitividad.

$>$ Plan Nacional de Educación y Patrimonio. Ministerio ECyD. $>$ Proyecto FCT-14-9015, Convocatoria de ayudas para el fomento de la cultura científica, tecnológica y de la innovación. Ministerio de Economía y Competitividad.

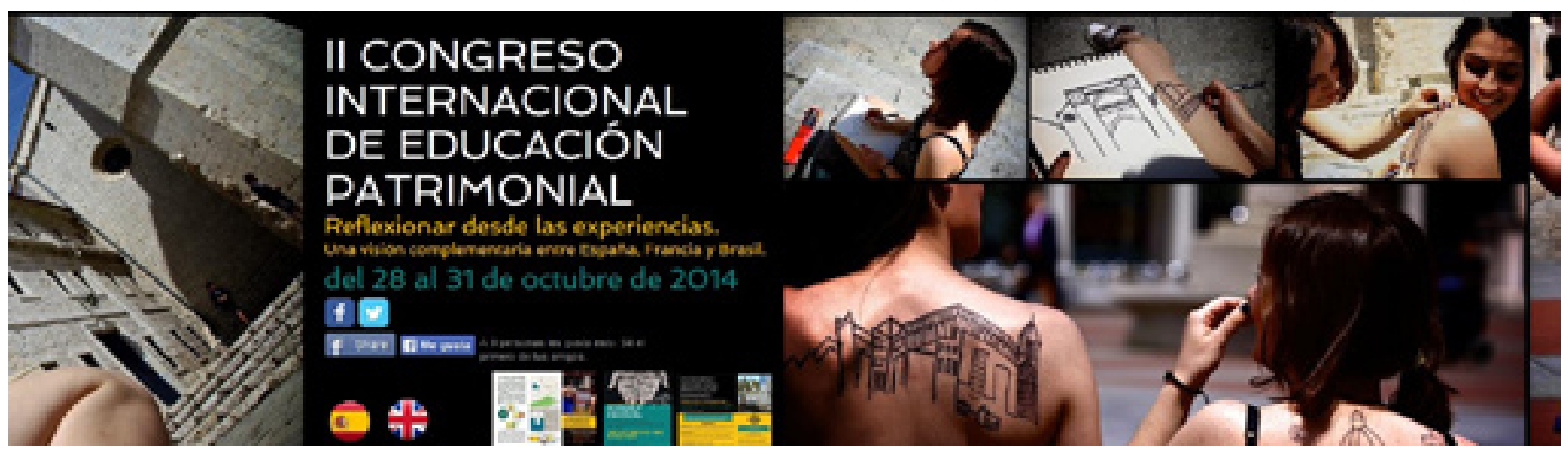

Detalle de la web del II Congreso internacional de educación patrimonial

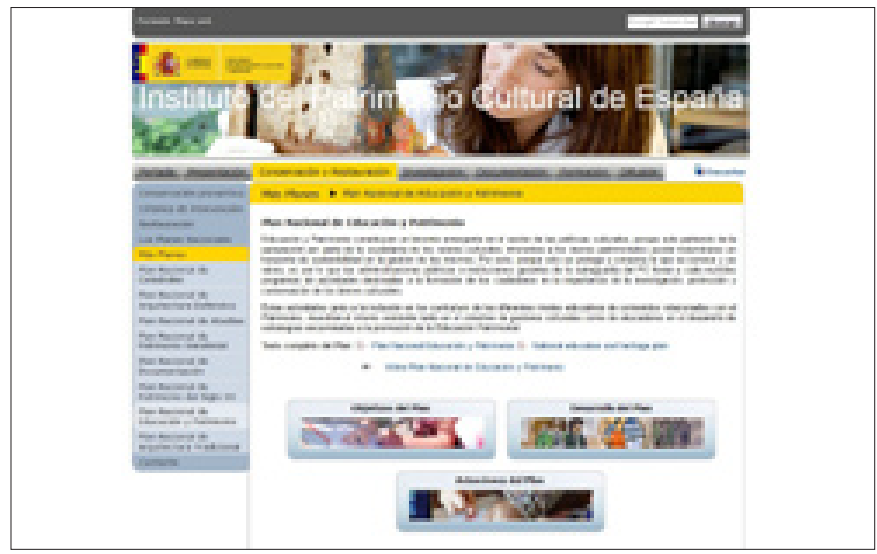

Web del Plan Nacional de Educación y Patrimonio

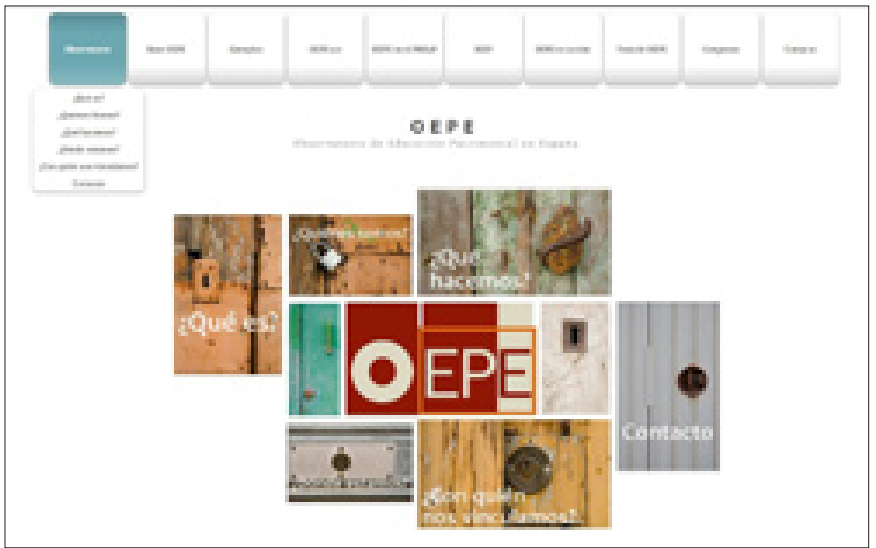

Web del Observatorio de Educación Patrimonial en España 